\title{
Cultural Accommodation: Hybridity and the Framing of Social Obligation
}

\author{
Daphna Oyserman, Izumi Sakamoto, and Armand Lauffer \\ University of Michigan
}

\begin{abstract}
Implications of cultural accommodation-hybridization were explored within the framework of individualism-collectivism. Individualism highlights the personal and centralizes individuals as the unit of analyses, whereas collectivism highlights the social and contextualizes individuals as parts of connected social units. In 2 experiments, the ways in which individualism, collectivism, and identity salience influence social obligation to diverse others was explored. The authors varied the personal goal interrupted (achievement-pleasure), the target (individual-group), and focus (in-group-larger society) of social obligation within subjects. The authors hypothesized that collectivism would increase obligation to the in-group when identity was made salient; that individualism alone would dampen social obligation; and that cultural accommodation-hybridization (being high in both individualism and collectivism) would increase obligation to larger society.
\end{abstract}

If America works, it will be a place where thousands of cultures express themselves. (Meter, 1987)

Although one's everyday choices may appear on the surface to be idiosyncratic - the result of highly personalized goals, desires, and motivations - the field of cultural psychology suggests that these choices may in fact be colored by one's social representations of what it means to be a successful person, a good or moral person, a person of worth (e.g., Kagitcibasi, 1996; Oyserman \& Markus, 1993). The ways individuals organize experience, what seems right, natural and of worth, how individuals make sense of themselves, one's goals and motivations, all importantly depend on the ways these concepts are socially represented both generally within a society and specifi-

Daphna Oyserman, Institute for Social Research, University of Michigan; Izumi Sakamoto and Armand Lauffer, School of Social Work, University of Michigan.

Funding for this research came from a W. T. Grant Faculty Scholar award to Daphna Oyserman; from the Culture and Cognition Program, University of Michigan, to Izumi Sakamoto; and from the Office of the Vice President for Research, University of Michigan, to Daphna Oyserman and Armand Lauffer. We are grateful for this support.

The studies in this article were reported in part in a poster presented at the American Psychological Society, New York, New York, June 1995, and in papers presented at the Midwestern Psychological Association, Chicago, May 1996 and the International Psychology Congress, Montreal, Quebec, Canada, August 1996.

David Van Eck programmed the Clipper executable used for the studies. Robert San Juan, Sondra Schwartz, Eiichi Schimizu, and Akane Zusho ran the focus groups. In addition, Junko Boland, Stacey Kleinbaum, and Zannah Maas helped with data entry. Without the participation and sharing of the focus group participants we would not have been able to develop the measures for this study.

Correspondence concerning this article should be addressed to Daphna Oyserman, Research Center for Group Dynamics - Institute for Social Research, University of Michigan, Ann Arbor, Michigan 481061248. Electronic mail should be sent to daphna@umich.edu. cally within the sociocultural niches individuals occupy in that society (e.g., Kagitcibasi, 1996; Oyserman, Gant, \& Ager, 1995; Oyserman \& Markus, 1996; Shaver, Wu, \& Schwartz, 1992). The role of cultural context in the everyday understandings of individuals has been highlighted in cross-cultural work suggesting that cultures differ in both the ways life tasks are structured and the normative role of individual difference and social embeddedness (e.g., Hofstede, 1991; Markus \& Kitayama, 1991; Triandis, 1989). The insights gained from this work increasingly are being used to make sense of the ways individuals within heterogeneous societies such as the United States make choices and organize experience (e.g., Cameron \& Lalonde, 1994; Gurin, Hurtado, \& Peng, 1994; Kowalski \& Wolfe, 1994; Oyserman, 1993).

One important distinction made in the cross-cultural literature focuses on the degree of individualism versus collectivism within a cultural frame (e.g., Schwartz, 1990). Although the United States has often been used as the prototype of individualism, increased attention to the multiethnic, multicultural U.S. population has led to consensus that many Americans, particularly minorities, are likely to be socialized into both world individualistic and collectivist views (e.g., Phinney, 1996; Sampson, 1988). One of the promises of multiculturalism is that by affording individuals a chance to express their particularized identities, society as a whole will be strengthened (e.g., Fowers \& Richardson, 1996). One way that this might occur is through a process of cultural hybridization in which individuals and groups create a new multidimensional cultural frame, taking into account the values and goals of both individualism and collectivism.

Cultural hybridization is related to but distinct from acculturation assimilation - the adaptations individuals make when they move to a new culture or between cultural contexts (e.g., Berry, 1989). Hybridization involves the melding of cultural lenses or frames such that values and goals that were focused on one context are transposed to a new context. Hybridization has the potential of allowing individuals to express cultural values, even 
when the original contexts no longer exist, and also may create a bond or connection between individuals and their new contexts by allowing a socially approved forum to express their identities. Yet we know of no empirical evidence of the positive impact of hybridization on heterogeneous societies. In this article, we briefly sketch the ways in which individualism and collectivism are described with a focus on how these concepts can be usefully applied to the U.S. context. Our particular interest in the present research was the ways in which social obligation or cooperation is primed by these cultural frames. We propose that cultural hybridization primes individuals to view larger society as a focus of social obligation, and we present some initial empirical evidence of the positive implications of such hybridization.

\section{Individualism and Collectivism}

\section{Individualism}

The terms individualism and collectivism describe differences in social representations of personhood (e.g., Oyserman, 1993; Schweder \& Bourne, 1984; Triandis, 1995). Individualism carries with it representations of a successful person as one who develops personal goals, works to attain them, and knows how to have fun and how to enjoy him or herself. Within this framework, relationships are individually based; that is, they are not obligatory and continue only as long as they are mutually pleasing or worthwhile (e.g., Fiske, 1990; Sampson, 1988). Individualism primes a focus on individual freedom and personal goals (Triandis, 1995). The relational schemas (e.g., Baldwin, 1992) that make sense within an individualistic frame are based in collaboration and competition between the self and specific other individuals. Individuals are free to form relationships and alliances with any other, and if a relationship is not equitable or personally satisfying it can be dissolved and a new relationship established with someone else. Further, given the focus on the individual, one's goals and feelings are weighted heavily, and individuals are socialized to assess and monitor their internal states. Individualists are interested in whether they are happy, the state of their self-esteem (Markus, Mullally, \& Kitayama, 1996). These foci of individualism have been termed utilitarian individualism and expressive individualism respectively, and are viewed as central to American individualism (Bellah, Madsen, Sullivan, Swidler, \& Tipton, 1985; Wilkinson, 1992). Social obligation per se is not central to this world view. Thus, individualism has been criticized as promoting an empty self, one devoid of family and community (Cushman, 1990) as well as promoting a saturated self, one overloaded with information because no other structure is considered of value but one's own self (Gergen, 1991). American individualism has been described as focused on the "' 'M-Factor' - movement, migration, and mobility" (Wilkinson, 1992, p. 80, describing the work of George Pierson, 1963). Ties do not bind, and individualists learn to get along with and cooperate with diverse others because they are all potential interaction partners who may benefit the self in the future.

\section{Collectivism}

Whereas individualism primes a focus on the self and assumes that relationships are secondary to that self and changeable, collectivism primes a focus on social roles and the group, with the assumption that group membership is permanent (e.g., Phinney \& Cobb, 1996). Collectivism often involves a specific sense of place and rootedness (e.g., Triandis, 1996), with a focus on social roles and fulfilling duties (e.g., Ames, Dissanayake, \& Kasulis, 1994). Success in a collectivist context is represented as sensitive fulfillment of one's duties and obligations toward one's in-group (e.g., Markus \& Kitayama, 1991; Oyserman \& Markus, 1993, 1996; Singalis, 1994; Triandis, 1995). Within a collectivist world view, the social group and the social roles emanating from the group are understood to be the basic unit such that collaboration flows more naturally within the in-group and competition seems part of the definition of out-group membership (Oyserman, 1993). One's relationships are set by one's group memberships and social roles, and these carry with them obligations that are not necessarily based on questions of equity. The relational schemas (e.g., Baldwin, 1992) that make sense within a collectivistic frame deal with obligations to the ingroup and specific members of the in-group. To the extent that an individual is viewed as an out-group member, relational schemas may be of a completely different sort such that social obligation would be minimal or nonexistent, replaced by a sense of competition or conflict (e.g., Oyserman, 1993; Triandis, 1995). Collectivism carries with it a sense of nested in-groupness; depending on the context the group may be restricted to family, clan, ethnic group, or nation (Triandis, 1995). Although social obligation to the in-group flows naturally from collectivism, the in-group itself is viewed as made up of blood connections, therefore it cannot be joined as can the affinity groupings of individualists. In this sense, collectivism might be thought of as a social correlate of the kinds of neo-Darwinian decision rules for altruism described recently by Burnstein and his colleagues (Burnstein, Crandall, \& Kitayama, 1994). Collectivism promotes particularistic rather than universal social obligation.

\section{Hybridization and Social Obligation}

Cultural hybridization may be said to occur when an individual or group is exposed to and influenced by more than one cultural context. We propose that socialization within more or less individualistic or collectivism cultural contexts, and one's internal representations of these cultural frames, is likely to influence the extent to which one will take into account an other's needs. However, the interplay between individualism and collectivism - between a focus on one's own goals and a focus on one's social obligations-has not received sufficient attention. How are these value systems melded? It is possible, for example, that the melding of individualism and collectivism results in more context-specific responses such that one or the other system is evoked in specific situations. Thus, individuals raised in both cultural frames may value personal happiness, personal success, and personal goal attainments in frameworks viewed as irrelevant to one's social obligations, in school for example, but fulfill social obligations in group contexts in which they are evoked. Such cultural accommodation could be a form of assimilation, freeing individuals to behave appropriately as individualists in larger societal contexts while preserving collectivism as an in-group focus. Accommodating cultural frame to context is one form of cultural accommodation. Alternatively, 
individualism, with its focus on each individual as a potential relationship partner, may actually change the way social obligation is conceptualized rather than simply change the contexts in which it is carried out.

The literature on social obligation-altruism provides an overview of the issues raised in this research (e.g., Callero, 1986; Liberman, 1986; Piliavin \& Libby, 1986; Thompson, Cowan, \& Rosenhan, 1980; Williamson \& Clark, 1989). In their classic work, Latané and Darley (1970) proposed that individuals help when they decide a need exists or decide that it is their responsibility to help and that there is something that they can do to help. Yet the psychological altrusim-social obligation research tradition has failed to take cultural context into account, focusing instead on decontextualized individuals (Batson, 1995). This is in spite of the fact that concern about the interplay between individualism and social obligation has been raised for many decades in the sociological literature (e.g., Wilkinson, 1992). The psychological literature, as reviewed by Batson (1995), suggests that what may appear to be helping - altruism or social obligation - is really egoism-a way to benefit the self through material, social, and self-rewards; the avoidance of material, social, or self-punishments; or reduction of aversive arousal. From another perspective, the sociobiological literature has examined acts of altruism, seeking to demonstrate the ways in which these actions may increase the inclusive fitness of helpers (e.g., Batson, 1995). Burnstein, Crandall, and Kitayama (1994) demonstrated that what might appear to be altruism can be predicted by the extent to which such an act increases inclusive fitness. Such kin helping and helping due to social norms of reciprocity suggest that individuals will help those who have already helped them or who they believe can help them in the future.

It is possible that a collectivist world view is a social correlate of biological inclusive fitness and that the reciprocity norm focuses specifically on the in-group, or those who are likely to reciprocate in the future. However, as a social construct, collectivism and its impact on social obligation has yet to be assessed directly in this literature. In his review of the literature, Batson (1995) cited only one empirical study of what he termed collectivism. A study by Dawes, Van de Kragt, and Orbell (1990) showed that individuals will work for the benefit of their ingroup, not for their personal good, when group identity is made salient and a norm of cooperation is established. Although suggestive of an in-group sharing norm, this study did not assess collectivism, so it does not provide any direct evidence of the implications of this cultural construct.

\section{Interplay Between Individualism and Collectivism: Culture Clash or Acculturation?}

Whereas cross-cultural psychology has focused attention on cross-cultural differences in individualism and collectivism, the ethnic identity literature has explored ways in which minorities in the United States must make sense of themselves in terms of both in-group and larger societal perspectives (e.g., Crocker, Luhtanen, Blaine, \& Broadnax, 1994; Phinney, 1996). Models historically have focused on acculturation and assimilation of minorities into majority U.S. culture (e.g., Gordon, 1964; Kagitcibasi, 1996; Lonner \& Berry, 1989). Groups were assumed to be accepted into the host culture once they successfully replaced their customs, values, and beliefs with the customs, values, and beliefs of majority culture (e.g., Patel, Power, \& Bhavnagri, 1996). Assimilation in Gordon's (1964) classic model involved a number of components: cultural assimilation was described as adopting the norms of majority society, and structural assimilation was described as movement of the minority into the social structure of majority society. The assumption that social-structural conditions are what stand between minorities and assimilation into majority society is still central to researchers' thinking and policies (e.g., Phillips, 1991). However, recent reviews have suggested that assimilation is inadequate as a model of the experiences of ethnic minorities in that majority, individualistic culture is likely to contain elements that are viewed as inappropriate in terms of the minority group's own more collectivist cultural frames. Therefore, minority groups may seek to maintain a variety of stances other than an assimilationist one with regard to majority culture (e.g., LaFromboise, Coleman, \& Gerton, 1993; Phinney, 1996). This may be particularly true in the ways in which social relations and social obligation are conceptualized (e.g., Patel et al., 1996; Triandis, Kashima, Shimada, \& Villareal, 1986). Minorities within U.S. society may creatively work out solutions for integrating competing cultural demands. A culturally appropriate solution, for example, may involve the contextualization of appropriate behavior on the basis of social context. Within the terminology used to describe the self in Japan, appropriate responses would depend on whether an inside or outside perspective, an in front or behind appropriate self (e.g., Bachnik, 1992), had been elicited. In this way individuals may take on the values and beliefs of the host culture and accommodate to the host culture in the public sphere while maintaining the parent culture in the private sphere. Other alternatives run the gamut from maintaining only the parent culture-often by not engaging in the host public sphere and at the expense of becoming socially peripheralized-to seeking to embrace only the host culture. We propose that cultural accommodation or socialization to both individualism and collectivism is a possible stance, one that is particularly beneficial for a heterogeneous society because it shifts focus of relational schemas of obligation from the smaller in-group to larger society while engaging the individual in the mainstream of the host and parent cultures.

\section{Hypotheses}

Our studies sought to document the influence of individualistic and collectivistic cultural frames on social obligation. We hypothesized an interaction among the context of helping, identity salience, cultural frames, and socialization experiences. Specifically, we hypothesized the following:

1. Social obligation is context dependent. Cultures define worthy targets and foci of obligation, and obligation will be reduced when pitted against an important personal goal.

2. Collectivism will increase social obligation, and individualism will decrease it.

3. Collectivism and individualism will differ in the unit of obligation. Individualism will increase obligation to individuals; collectivism will increase obligation to groups, especially ingroups. 
4. Cultural accommodation (being high in both individualism and collectivism) will predict more in social obligation, faster response time, and higher confidence when the target of obligation is the larger society.

Each of these hypotheses was qualified by identity salience and socialization interaction effects. We expected effects to be stronger when individuals are reminded of their identities (salience manipulation ) and when individuals have been socialized within a cultural frame such that the identity will be chronically more salient (socialization effect).

In our first study we used a sample of Jewish American students. In our second study we used a sample of Asian and Asian American students. We chose these groups because although they are identifiable within U.S. culture, they also are highly structurally assimilated, allowing for variability in the focus of social obligation. This allowed us to study cultural accommodation without taking into account issues of overt structural barriers and prejudices. Minority groups (e.g., African Americans, Hispanic and Latino Americans, and Native Americans) who experience more overt structural barriers and prejudice may be limited in their ability either to take on a culturally accommodative stance or to act on this stance in a particular context.

\section{Study 1}

\section{Method}

\section{Sample}

Participants were Jewish American university students attending two midwestern universities $(N=93)$, all of whom were born in the United States. Students' mean age was 20.6 years, and their median grade point average (GPA) was 3.45 .

\section{Procedure}

Due to the small number of Jewish students in the student body, we attempted to locate a sample of Jewish students by means of a random sampling of the Hillel Foundation mailing list at two midwestern universities. We simply mailed the study to the students' home in the form of a computer disk to be completed and mailed back. We mailed 300 diskettes, 93 of which were returned. Participants were presented the study materials in a DOS-executable Clipper program (Gutierrez, 1994). Initial screens obtained information on gender so that all stories involved others with the same gender as the participant. As is described below, the order of presentation of the social obligation materials was controlled with a Latin square design, participants were randomly assigned to identity-salient or identity-not-salient conditions, and response times as well as responses were logged.

\section{Manipulations}

Identity salience. Because the impact of one's cultural frame may only come into play when one has been reminded of its relevance, we manipulated identity salience by manipulating the order of presentation of materials. Participants with even identification numbers received the identity-salient manipulation; that is, they responded to the cultural identity questions, which brought identity to mind, before receiving the scenarios. Participants with odd identification numbers responded to the scenarios first.

Social obligation. Participants were provided with a series of eight scenarios, one per screen. Each scenario described both a personal goal and a social obligation. Personal goals focused on pleasure (go to a friends', go to a concert, go on a picnic) or achievement (study for an exam, do a paper, get caught up with school work, take a summer job with professor). The target of social obligation was an individual (classmates, lab partners, a handicapped student, an acquaintance) or a group (social service or student service organizations), and the focus of social obligation was a member of one's in-group or larger U.S. society. Larger society groups were general social service (e.g., voter registration drive, Martin Luther King, Jr., Day planning committee, family services agency, volunteer in a soup kitchen) or individuals with nonethnic-specific names (e.g., Sam-Sara or Kyle-Kim) who needed help studying, were blind and needed to be read aloud to, needed help on class project, or needed to talk about their personal relationships. Ingroup level scenarios described obligation to the group, not a specific other (e.g., Jewish family services, purim carnival, help protest inflammatory campus speech entitled "Ethnic cleansing: What the Bosnians have learned from Israel"). In-group individual-level scenarios were the same as the larger society individual scenarios except that an identifier phrase such as "Who you met at Hillel" was added to trigger ingroup membership. Names were developed with a focus group of Jewish students; we chose names viewed as ethnically- and religiously neutral. Names then were randomly rotated through the Latin square such that each participant received the names in a random, non-story-based order.

We counterbalanced order of presentation so that participants received half the scenarios with their personal goal described first and half with the social obligation first (no effect of counterbalancing was found). The Latin square design meant that all order and content combinations were possible ( 64 cells), and each respondent received a scenario set that was balanced for each content and order. Thus, a participants' eight scenarios contained four own goal first and four social obligation first; four social obligation to individual and four social obligation to group; four social obligation to in-group and four social obligation to larger society; and four social obligation interrupts personal achievement goal and four social obligation interrupts pleasure goal segments. This technique allowed for within-subject analysis of the impact of each of these content variables across the scenarios, providing a mean score across four different scenarios for each variable. The full scenario remained on the screen until the respondent marked their behavioral choice and their confidence in that choice.

\section{Measures}

Collectivism. Collectivism (COL) was measured with a seven-item, 5-point Likert-type scale adapted from Oyserman (1993). The items were "I feel a strong sense of belonging to the Jewish people," "As a Jew my values may be different from those of others," "I feel a strong attachment to the Jewish people," "If a person knows I am a Jew, he or she will know a lot about me," "To understand who I am, you have to see me with other Jewish people," "Willingness to take action to help the Jewish people is a sign of maturity," and "When I hear about political events, my first thought is about how this might impact the Jews." Responses ranged from 1 (strongly disagree) to 5 (strongly agree; $M=2.99$, range $=2.23-3.88, \alpha=.85$ ) .

Individualism. Individualism (IND) was measured with a sevenitem, 5-point Likert-type scale adapted from Oyserman (1993). The items were "I am different from everyone else, unique," "Decisions I make on my own are the best," "My achievements are central to who I am," "If I like an idea, I don't care what anyone else thinks about it," "Others cannot know me as I know myself," "I expect that my work will be central to my identity," and "It is important to me to have my own opinions." Responses ranged from 1 (strongly disagree) to 5 ( strongly agree; $M=3.59$, range $=2.72-4.48, \alpha=.57$ ). As found in previous studies (e.g., Oyserman, 1993), individualism and collectivism were not significantly correlated $(r=.13 p>.10)$. The salience manipu- 
lation was hypothesized to make IND and COL salient in decision making, not to influence level of IND and COL. In fact, the identity-salience manipulation did not influence mean individualism collectivism scores.

Cultural accommodation. Accommodation-hybridization was defined as being high in both individualism and collectivism. We used a median-split technique to identify this high-high group $(n=24)$. In addition, participants rated the importance (on a 5-point Likert scale ranging from $1=$ very unimportant to $5=$ very important) of being American $(M=3.98)$ and being Jewish $(M=4.26)$. As a check on our operationalization of cultural accommodation, we assessed the importance of being both American and Jewish for the culturally accommodating group (high-high on IND-COL). Analyses of variance (ANOVAs) showed a two-way interaction significant at the trend level, $F(1,86)=3.17, p=.08$, such that the culturally accommodating group viewed being American as more important than did the other participants. In addition, there was a significant main effect of COL, $F(1,86)=$ $28.38, p<.001$, such that the high-COL group viewed being Jewish as more important than did the low-COL group.

Socialization. Socialization was assessed by asking participants eight questions, four each about their experiences before and after bar mitzvah age: "how many years did you attend Sunday school? Hebrew school? Jewish summer camp (or gone to Israel)?" "How often did you attend synagogue or temple?'" $(\alpha=.76)$. These items were asked at the end of the study for all participants. Socialization was dichotomized as a median split: High-socialization participants received much in-group socialization, whereas low-socialization participants had received little. Socialization was not significantly correlated with either IND or COL, thus amount of in-group socialization neither increased collectivism nor decreased individualism. Because socialization may focus directly on values of social obligation, it was included in further analyses.

\section{Dependent Measures}

Three social obligation variables were assessed: level of obligation, latency of response, and confidence.

Level of obligation. At the end of each scenario, participants could choose to carry out a social obligation or pursue personal goals. Level of social obligation was coded as 1 (carry out social obligation) or 0 (pursue own goal; $M=.61$, range $=0-1$ ). So as not to capitalize on order effects, we randomized the order of the two behavioral choices depending on whether the respondent opened the screen on an odd or even second. In addition, we wrote the personal goal and social obligation choices in as neutral a form as possible (e.g., "study alone" vs. "study with him" for a scenario involving an upcoming exam and an acquaintance's request for study help).

Latency. This variable was obtained from the internal computer clock reading of the time from when the scenario appeared on the screen until the keystroke marking behavioral choice $(M=158.23$, range = $34.50-318.63 \mathrm{~s}$ )

Confidence. After marking a behavioral choice, the query "how sure are you?' appeared on screen, followed by a line segment from 0 to 100. Respondents moved the cursor to show how sure they were. The confidence measure was constructed as the product of behavioral choice and percentage certainty. We recoded personal goal choices as -1 to obtain scores from -100 to +100 , where -100 represented $100 \%$ certainty and a personal goal behavioral choice and +100 represented $100 \%$ certainty and a social obligation behavioral choice $(M=19.24$, range $=-99.00$ to 84.25 ).

\section{Results}

\section{Overview of Analyses}

To assess the impact of cultural factors and context with regard to each of the dependent variables-level, confidence, and latency - we used a mixed-effect ANOVA. We first assessed the impact of the between-subjects differences in cultural factors without taking the context of social obligation (personal goal being interrupted, target, and focus of obligation ) into account. We then added context in a series of repeated measures ANOVAs, one set predicting level of obligation, the second set predicting latency, and the final set predicting confidence. Between-subject measures were IND (high-low), COL (highlow), and identity salience (yes-no). The additional betweensubjects measure, socialization experiences (high-low), was also included in the equations, but because of our sample size, we could not include both salience and socialization at the same time. ${ }^{1}$ To conserve space, we report findings from these analyses only when socialization had a main or interactive effect on obligation. A summary of all significant findings by context (not including main effects of IND and COL) from Study 1 and Study 2 is presented in Table 1.

\section{Level of Obligation}

Mean social obligation. The hypothesized main effect of $\mathrm{COL}$ was found such that collectivists reported more social obligation, $F(1,81)=4.06, p<.05$. No effects of IND or identity salience were found. The ways in which the specific contexts of social obligation may interplay with cultural factors and identity salience in predicting social obligation were then explored with repeated measures ANOVAs.

Personal goal being interrupted (pleasure vs. achievement). A within-subjects effect of personal goal was found, $F(1,80)$ $=46.88, p<.001$, such that obligation was higher when the personal goal being interrupted was pleasure rather than achievement focused. The hypothesized pro-obligation effect of collectivism was found at a trend level, $F(1,80)=2.98, p=$ .09. There was a trend toward a three-way IND $\times$ Identity Salience $\times$ Personal Goal interaction, $F(1,80)=3.48, p=$ .07 . As hypothesized, individualists helped less when identity was salient and an important personal goal was interrupted (that is, an achievement-focused goal). Individualism reduced social obligation when identity was salient and social obligation competed with an important personal goal.

Target of obligation (individual vs. group). We found a significant four-way IND $\times$ COL $\times$ Identity Salience $\times$ Target of Social Obligation interaction, $F(1,80)=4.17, p<.05$, which moderated an Identity Salience $\times$ Target of Socialization interaction, $F(1,80)=3.39 p=.07$. As hypothesized, when identity was salient, high individualism coupled with low collectivism decreased obligation to help groups. When socialization was added as the third, between-subjects measure, a trend-level three-way COL $\times$ Socialization $\times$ Target of Social Obligation interaction was found, $F(1,77)=3.59, p=.06$. When the target of obligation was a group, in-group cultural socialization mitigated the negative effect of low collectivism on obligation. Our data thus suggest first that social obligation differs when the target is an individual or a group, second that collectivism

\footnotetext{
'Similarly, although we could have used gender in the repeated measure analysis, we had no gender-specific hypotheses, and initial analyses suggested that gender did not correlate with our measures. Therefore, we did not include gender in our analyses.
} 
Table 1

Summary of Significant Findings by Hypothesis, Study, and Dependent Variable

\begin{tabular}{|c|c|c|c|c|}
\hline Dependent variable & Context & Finding & $F$ & $d f$ \\
\hline \multicolumn{5}{|c|}{ Hypothesis 1: Social obligation is context dependent } \\
\hline \multicolumn{5}{|l|}{ Study 1} \\
\hline \multirow[t]{3}{*}{ Level of obligation } & Personal goal & $\begin{array}{l}\text { Social obligation is higher when the personal goal interrupted is pleasure } \\
\text { focused }\end{array}$ & $46.88 * * *$ & 1,80 \\
\hline & Target & Identity salience increases obligation toward individuals & $3.39 \dagger$ & 1,80 \\
\hline & Focus & Social obligation is higher to larger society & $11.49^{* * *}$ & 1,84 \\
\hline Latency & Personal goal & Quicker response when pleasure goal is interrupted & $10.28 * *$ & 1,80 \\
\hline \multirow[t]{3}{*}{ Confidence } & Personal goal & Confidence in obligation is higher when pleasure goal is interrupted & $77.17 * * *$ & 1,82 \\
\hline & Focus & Confidence in obligation is higher to larger society & $5.13^{*}$ & 1,80 \\
\hline & & $\begin{array}{l}\text { Identity salience reduces confidence in obligation to larger society and increases } \\
\text { confidence in obligation to in-group }\end{array}$ & $7.34 * *$ & 1,80 \\
\hline \multicolumn{5}{|c|}{ 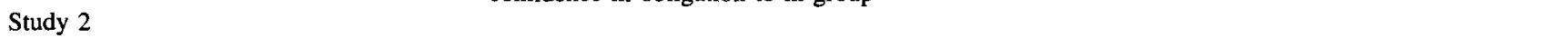 } \\
\hline \multirow[t]{3}{*}{ Level of obligation } & Personal goal & Obligation is lower when the personal goal interrupted is pleasure focused & $102.70^{* * *}$ & 1,75 \\
\hline & Focus & Obligation is higher for in-group & $7.10^{* *}$ & 1,71 \\
\hline & & Identity salience increases obligation to larger society & $36.36 * * *$ & 1,71 \\
\hline & Focus & When identity is salient, respond more quickly to larger societal obligations & $3.05 \dagger$ & 1,71 \\
\hline \multirow[t]{2}{*}{ Confidence } & Target & Exposure to U.S. culture reduces confidence in helping groups, not individuals & $2.84 \dagger$ & 1,67 \\
\hline & Focus & When identity is salient, confidence in helping larger society is increased & $30.74 * * *$ & 1,71 \\
\hline
\end{tabular}

Hypothesis 2: Social obligation is influenced by cultural frame

Study 1

\begin{tabular}{|c|c|c|c|c|}
\hline Level of obligation & Personal goal & For collectivists, social obligation is higher & $2.98 \dagger$ & 1,80 \\
\hline & Focus & For collectivists, social obligation is higher & $4.19^{*}$ & 1,84 \\
\hline Latency & Personal goal & When identity is salient, collectivists respond more quickly & $3.23 \dagger$ & 1,80 \\
\hline & & $\begin{array}{l}\text { Collectivists who are highly socialized in their in-group culture respond more } \\
\text { quickly }\end{array}$ & $3.71 \dagger$ & 1,77 \\
\hline & Target & When identity is salient collectivists respond more quickly & $3.73 \dagger$ & 1,80 \\
\hline & & $\begin{array}{l}\text { Collectivists who are highly socialized in their in-group culture respond more } \\
\text { quickly }\end{array}$ & $3.87^{*}$ & 1,77 \\
\hline & Focus & When identity is salient collectivists respond more quickly & $3.53 \dagger$ & 1,80 \\
\hline & & $\begin{array}{l}\text { Collectivists who are highly socialized in their in-group culture respond more } \\
\text { quickly }\end{array}$ & $3.99 *$ & 1,77 \\
\hline Confidence & Personal goal & Confidence is higher for collectivists & $4.80^{*}$ & 1,82 \\
\hline & Target & Confidence is higher for collectivists & $4.15 *$ & 1,79 \\
\hline & Focus & Confidence is higher for collectivists & $4.42 *$ & 1,80 \\
\hline cudy 2 & & & & \\
\hline Level of obligation & & No significant findings & - & - \\
\hline Latency & Target & When identity is salient, collectivists respond more quickly & $3.73 \dagger$ & 1,80 \\
\hline & & Collectivists exposed to U.S. culture respond more quickly & $3.87^{*}$ & \\
\hline Confidence & & No significant findings & - & \\
\hline
\end{tabular}

Hypothesis 3: The influence of cultural frame on social obligation is context dependent

Study 1

Level of obligation Personal goal When identity is salient, individualists interrupted in an achievement goal feel less obligated

Target Socialization to in-group culture mitigates the dampening effect of low collectivism on obligation toward groups

When identity is salient, collectivists respond more quickly to in-group needs

Latency $\quad$ Focus

Collectivists lacking socialization to in-group culture respond more slowly to the needs of larger society

Confidence

Study 2

Level of obligation Focus

Latency

No significant findings

Identity salience increases obligation to larger society for collectivists

When identity is salient, response to larger society obligations is faster

When identity is salient, individualists respond more quickly to obligations to larger society

Confidence

Personal goal When identity is salient, collectivists exposed to U.S. culture are less confident about social obligations when the pleasure goal interrupted is pleasure focused

Focus When identity is salient, collectivists are more confident about meeting obligations to larger society

$\begin{array}{lr}3.48 \dagger & 1,80 \\ 3.59 \dagger & 1,77 \\ & \\ 6.08^{*} & 1,80 \\ 5.20^{*} & 1,77 \\ & \\ - & - \\ 5.56^{*} & 1,71 \\ 3.62 \dagger & 1,71 \\ 3.77 \dagger & 1,71 \\ 3.06 * & 1,71 \\ & \\ 4.00^{*} & 1,71\end{array}$

(Table continues) 
Table 1 (continued)

\begin{tabular}{|c|c|c|c|c|}
\hline Dependent variable & Context & Finding & $F$ & $d f$ \\
\hline \multicolumn{5}{|c|}{ Hypothesis 4: Cultural accomodation influences social obligation } \\
\hline \multicolumn{5}{|l|}{ Study 1} \\
\hline \multirow[t]{2}{*}{ Level of obligation } & Target & $\begin{array}{l}\text { When identity is salient, high individualism coupled with low collectivism } \\
\text { reduces obligation to groups }\end{array}$ & $4.17 *$ & 1,80 \\
\hline & Focus & $\begin{array}{l}\text { When identity is salient, cultural accomodators feel more obligated to larger } \\
\text { society }\end{array}$ & $3.14+$ & 1,84 \\
\hline Latency & & No significant findings & & \\
\hline \multirow[t]{2}{*}{ Confidence } & Target & $\begin{array}{l}\text { When identity is salient, cultural accomodators feel more obligated toward } \\
\text { individuals }\end{array}$ & $3.95^{*}$ & 1,84 \\
\hline & Focus & $\begin{array}{l}\text { Cultural accomodators are more confident about meeting obligations to larger } \\
\text { society }\end{array}$ & $3.52 \dagger$ & 1,84 \\
\hline \multicolumn{5}{|c|}{ 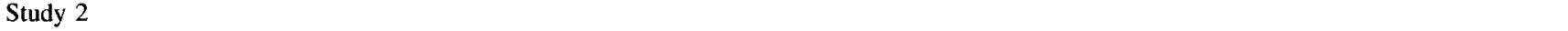 } \\
\hline Level of obligation & Target & When identity is salient, cultural accomodators feel less obligated to individuals & $2.84 *$ & 1,71 \\
\hline \multirow[t]{5}{*}{ Latency } & Personal goal & $\begin{array}{l}\text { Cultural accomodators respond more quickly whenever social obligation is } \\
\text { elicited }\end{array}$ & $4.25 *$ & 1,71 \\
\hline & Focus & $\begin{array}{l}\text { Individualists with little exposure to U.S. culture who are low in collectivism } \\
\text { respond slowly to social obligation elicitors }\end{array}$ & $2.93 \dagger$ & 2,67 \\
\hline & & Cultural accomodators respond more quickly to social obligation elicitors & $4.25^{*}$ & 1,71 \\
\hline & & $\begin{array}{l}\text { When identity is salient, cultural accomodators respond more quickly to social } \\
\text { obligation elicitors }\end{array}$ & $3.44 \dagger$ & 1,71 \\
\hline & & $\begin{array}{l}\text { Cultural accomodators exposed to U.S. culture respond more quickly to social } \\
\text { obligation elicitors }\end{array}$ & $2.93 \dagger$ & 2,67 \\
\hline Confidence & & No significant findings & & \\
\hline
\end{tabular}

Note. See Hypotheses section for full elaboration of each hypothesis.

$\dagger p<.10$ (marginally significant). ${ }^{*} p<.05 .{ }^{* *} p<.01 .^{* * *} p<.001$.

may increase obligation and individualism may decrease obligation when identity is salient and the target of obligation is a group, and third that ethnic or cultural socialization may mitigate the dampening effects of low collectivism on social obligation.

Focus of obligation (in-group vs. larger society). When only individualism, collectivism, and focus of social obligation were entered into the equation we found a main between-subjects effect of COL, $F(1,84)=4.19, p<.05$, and a withinsubjects effect of focus of social obligation, $F(1,84)=11.49$, $p<.001$, such that social obligation was higher to larger society and high collectivism increased social obligation. In addition we found a trend toward a three-way IND $\times \mathrm{COL} \times$ Focus of Social Obligation interaction, $F(1,84)=3.14, p=.08$. As hypothesized, collectivism increased social obligation and individualism reduced social obligation when not held in check by high collectivism. Social obligation is higher to larger society.

In general, effects followed our hypotheses with regard to the competing effects of individualism and collectivism. A main effect of collectivism was found such that collectivism increased social obligation. The hypothesized effect of individualism was found only when identity was made salient and social obligation was costly to individualistic goals. Thus, when salient, individualism reduced social obligation when obligation competed with important personal goals or when the target of obligation was a group. Formal socialization within the context of ethnic-religious identity played a less central role than expected. It neither correlated with level of individualism or collectivism nor had a direct impact on social obligation. However, socialization mitigated the negative effect of low collectivism on social obligation to groups. We now turn to the latency analyses.

\section{Latency of Obligation Response}

Mean latency. We found a trend toward a Salience $\times \mathrm{COL}$ interaction effect on mean latency across contexts, $F(1,80)=$ $3.53, p=.06$. As hypothesized, identity salience reduced decision time for high collectivists. When socialization was added as the third, between-subjects variable, only a main effect of COL was found, $F(1,78)=4.46, p<.05$. Collectivism reduced judgment latency. The interplay between cultural factors and context is examined below.

Personal goal being interrupted (pleasure vs. achievement). We found a main within-subjects effect of personal goal, $F(1$, $80)=10.28, p<.01$, such that latency was less when the goal interrupted was pleasure focused. There was also a trend toward a two-way COL $\times$ Identity Salience interaction, $F(1,80)=$ $3.23, p=.08$. As hypothesized, collectivism increased judgment speed when identity was salient. When socialization was added as the third between-subjects variable, we found a trend toward a two-way $\mathrm{COL} \times$ Socialization interaction, $F(1,77)=3.71, p$ $=.06$, such that being high in both collectivism and socialization decreased decision time. Socialization and collectivism act in tandem to increase speed of social obligation judgments.

Target of obligation (individual vs. group). We found a trend for a two-way COL $\times$ Identity Salience interaction, $F(1$, $80)=3.73, p=.06$. As hypothesized, collectivism reduced response time when identity was salient. When socialization was added as the third between-subjects variable, we found a twoway $\mathrm{COL} \times$ Socialization interaction, $F(1,77)=3.87, p=$ .05 , such that when socialization was high, collectivism reduced response time. As hypothesized, identity salient and highly socialized collectivists responded quickly to social obligation. 
Focus of obligation (in-group vs. larger society). A significant three-way COL $\times$ Identity Salience $\times$ Focus interaction was found, $F(1,80)=6.08, p<.05$. As hypothesized, collectivism reduced response time when identity was salient, especially when the target of obligation was the in-group. When socialization was added as a third between-subjects variable, we found a significant two-way COL $\times$ Socialization interaction, $F(1$, $77)=3.99, p<.05$, as well as a significant three-way COL $\times$ Socialization $\times$ Focus interaction, $F(1,77)=5.20, p<.05$. Being high only in collectivism or only in socialization had a dampening effect on latency when the focus of obligation was larger society. The posited positive effects of collectivism were found when identity was made salient or when ethnic socialization was high.

In general, the hypothesized effects of collectivism on latency were found across contexts. High collectivists who had a large amount of in-group socialization were quick in their judgments. When identity was made salient, collectivists increased judgment speed for in-group obligations; however, individualism did not have any impact on decision latency.

\section{Confidence in Judgment}

Mean confidence. The hypothesized main effect of COL was found such that collectivists reported more confidence in social obligation across contexts, $F(1,80)=5.34, p<.05$. No effects of IND or identity salience were found. We then examined the impact of context separately.

Personal goal being interrupted (pleasure vs. achievement). Neither identity salience nor socialization predicted confidence. With regard to the impact of individualism, collectivism, and type of personal goal, we found a main between-subjects effect of COL, $F(1,82)=4.80, p<.05$, and a within-subjects effect of type of personal goal interrupted, $F(1,82)=77.17, p<$ .001 , such that, as hypothesized, confidence in social obligation was higher for high collectivists and when the personal goal being interrupted was less central (pleasure focused).

Target of obligation (individual vs. group). We found a main between-subjects effect of COL, $F(1,79)=4.15, p<$ .05 , such that, as hypothesized, confidence in social obligation was higher for high collectivists. There was also a significant four-way IND $\times$ COL $\times$ Identity Salience $\times$ Target interaction, $F(1,79)=3.95, p=.05$. As hypothesized, confidence was lowest for high individualists-low collectivists when identity was salient and the target of obligation was a group. Cultural accommodation (high individualism-high collectivism) was related to increased confidence in helping when identity was salient and the target of obligation was an individual.

Focus of obligation (in-group vs. larger society). We found a main between-subjects effect of COL, $F(1,80)=4.42, p<$ .05 , and a within-subjects effect of focus, $F(1,80)=5.13, p$ $<.05$, such that, as hypothesized, collectivism increased confidence. Confidence in obligation was higher when the focus was on larger society. The effect of focus was modified by a significant two-way Identity Salience $\times$ Focus interaction, $F(1,80)$ $=7.34, p<.01$. When identity was made salient, confidence in obligation to larger society decreased and confidence in obligation to the in-group increased. When only IND and COL were used as between-subject measures, we found a trend toward a three-way IND $\times$ COL $\times$ Focus interaction, $F(1,84)=3.52$, $p=.06$, reflecting the hypothesized positive impact of cultural accommodation (high individualism-high collectivism) on increased confidence in obligation to larger society.

In general, we found the hypothesized effect of collectivism on decision confidence. Identity salience increased confidence in in-group social obligation for collectivists. When identity was salient, high individualism combined with low collectivism reduced confidence in obligation toward groups. Cultural accommodators were more confident in their obligation to larger society.

\section{Discussion}

The hypothesized positive effect of collectivism on social obligation was generally found-high collectivists felt more socially obligated, were more confident in their decisions, and, when identity was made salient, responded quicker. In addition, we found the hypothesized negative effect of individualism, albeit a weaker effect than that of collectivism. Individualism reduced social obligation when identity was made salient and the personal goal being interrupted was important or the target of obligation was a group and collectivism was also low. With regard to confidence, the negative effective of individualism was found again, especially when identity was made salient and the target was a group, not an individual. Identity salience facilitated confidence in judgments about in-group obligation, not larger society obligation. Evidence of the hypothesized impact of cultural accommodation - being high in both individualism and collectivism - was found in the analyses of confidence in social obligation to larger society. These findings suggest that collectivism is related to obligation as suggested by the literature and that this positive implication of collectivism can carry over to larger society when cultural hybridization occurs such as with the high individualism and high collectivism respondents in this study.

In Study 2, we attempted to replicate these findings with a very different minority group that also carries a collectivist tradition-Asians and Asian Americans. The Asian and Asian American group allowed us to test the hypothesis related to cultural accommodation more directly in that this group contained more recent arrivals to the U.S. cultural context. This allowed us to assess effects of exposure to individualism. In addition, to the extent that our findings regarding the impact of individualism and collectivism generalize across these two very diverse groups, we could have more confidence in their generalizability. Our hypotheses for Study 2 remained the same as for Study 1.

Study 2

Method

\section{Sample}

Our sample consisted of Asian and Asian American students ( $N=$ 80) whose mean age was 19.77 years and whose mean GPA was 3.19 Of these students, 34 were born in the United States, 14 were naturalized citizens who had lived in this country 5 or more years, and 32 were noncitizens who had lived in this country less than 5 years. Of the 
students who did not give their nationality as American, the majority stated their nationalities were Chinese, Japanese, or Korean, in descending order of frequency.

\section{Procedure}

The procedure was modified from Study 1 such that rather than attempting to locate students through student organizations, we used a standard prescreening and participant pool procedure. Students who identified themselves as Asian or Asian American as part of an omnibus prescreening questionnaire completed the study in small groups at a university computer laboratory in partial fulfillment of their participant pool requirements. We used the DOS-based Clipper (Gutierrez, 1994) executable program, as we had in Study 1. However, because the participants in this study were heterogeneous, we asked them to specify the way in which they identified themselves in the initial screen. Fourteen possibilities and an open write-in space were provided. The specific identifier the participant chose was used to key all of the scenarios so that in-group names were those our focus group identified as typical of the group, whereas larger society names were short names viewed by our focus group as "American." Because Asian Americans often do not maintain ethnically based first names, names were presented as initials and family names. For example, for a Chinese participant such names as Peng and Song appeared in in-group scenarios whereas for a Korean participant examples of names were Kim and Lee.

\section{Manipulation}

Identity salience. As in Study 1, identity salience was manipulated by means of order of presentation of materials. Respondents with even identification numbers received the identity salient manipulation, responding to the cultural frame questions first and thus bringing identity to mind before receiving the scenarios. Respondents with odd identification numbers responded to the scenarios before the cultural frame questions.

Social obligation. As in Study 1, participants were provided with a series of eight scenarios, one per screen, with each scenario containing a personal goal and a social obligation; order was again counterbalanced. As before, no effect of order of presentation of personal goal versus social obligation was found. Scenarios remained the same as Study 1 where possible. Some of the larger society social obligation scenarios were changed after focus groups revealed that Asian students did not believe that some of these obligations were relevant to them. Thus the Martin Luther King, Jr., Day planning committee scenario was changed to helping at an English as a second language program. Similarly, ingroup scenarios were made relevant. Thus, the inflammatory speech was no longer about what Bosnians can learn about ethnic cleansing from Israelis but rather a pro-Proposition 187 rally, and the Purim carnival became a New Year's festival.

\section{Measures}

Socialization exposure. Whereas in Study 1 all participants were born in the United States and most were likely to be at least third generation Americans, for the Asian subsample, we used questions about birth place, nationality, and number of years in the country to construct a measure of exposure to U.S. culture and lifestyle and the likelihood of acculturation, with born and raised in the United States $(n=34)$, naturalized and lived in the United States at least 5 years $(n=14)$, and born and raised elsewhere and in the United States less than 5 years ( $n$ $=31$ ) as descending levels of exposure.

Collectivism. COL was measured with the same seven-item, 5-point Likert-type scale used in Study 1 ( $M=2.90$, range $=2.20-3.39, \alpha=$ .82 ). The specific ethnic group the participant chose to self-identify with was embedded into the scale by the software. For example, if a participant was self-described as Chinese, items were "I feel a strong sense of belonging to the Chinese people," "As a Chinese person my values may be different from those of others," "I feel a strong attachment to the Chinese people," "If a person knows I am Chinese, he or she will know a lot about me," "To understand who I am, you have to see me with other Chinese people," "Willingness to take action to help the Chinese people is a sign of maturity," and "When I hear about political events, my first thought is about how this might impact the Chinese people.' Exposure to U.S. culture predicted level of $\operatorname{COL}, F(2,78)=$ $4.23, p=.02$, with those least exposed to U.S. lifestyle and cultural frame higher in collectivism.

Individualism. IND was measured with the same seven-item, 5-point Likert-type scale used in Study $1(M=3.70$, range $=3.01-4.41, \alpha=$ $.58)$. Exposure to U.S. culture did not predict level of IND, $F(2,78)$ $=1.57, p>.10$, and IND and COL were not correlated with one another other $(r=-.04, p>.10)$.

\section{Dependent Measures}

Each of the dependent measures was coded as in Study 1. Level of obligation was coded as 1 (carry out social obligation) and 0 (pursue own goal; $M=.55$, range $=.25-1.00$ ). Mean level of social obligation was thus similar across Study 1 and Study 2 (Study $1 ; M=.61$, range $=0-1)$. Latency $(M=126.06$, range $=17.50-559.00 \mathrm{~s})$ was also similar across the two studies (Study $1 ; M=158.23$, range $=34.50$ 318.63). However, confidence ( $M=0.14$, range $=-.88$ to 1.38 ) ratings differed by study, with Study 1 participant responses showing much higher certainty and variability (Study $1 ; M=19.24$, range $=-99.00$ to 84.25 ).

\section{Results}

Analyses followed Study 1; we analyzed the impact of the cultural variables both with and without context effects by using IND, COL, and identity salience as between-subject independent variables. As before, we repeated analyses with the cultural exposure variable replacing the identity salience variable, and again these findings are reported only when cultural exposure had main or interactive effects on obligation.

\section{Level of Obligation}

Mean obligation. No main or interaction effects of IND, COL, or identity salience were found when mean social obligation was used as the dependent variable. The interplay between cultural factors and context on social obligation is presented below on the basis of repeated measures ANOVAs.

Personal goal being interrupted (pleasure vs. achievement). A significant within-subjects effect of type of personal goal interrupted was found, $F(1,75)=102.70, p<.001$. When the personal goal being interrupted was pleasure focused, participants were less likely to help, a finding that is the reverse of Study 1.

Target of obligation (individual vs. group). A significant four-way IND $\times$ COL $\times$ Identity Salience $\times$ Target was found, $F(1,71)=2.84, p<.05$. When the target of potential obligation was an individual, social obligation decreased for identity salient high collectivists-high individualists.

Focus of obligation (in-group vs. larger society). A main effect of focus was found, $F(1,71)=7.10, p=.01$. As hypothesized, social obligation was higher for the in-group than for larger society. We also found a significant two-way Identity 
Salience $\times$ Focus interaction, $F(1,71)=36.36, p<.001$, and a three-way COL $\times$ Identity Salience $\times$ Focus interaction, $F(1$, $71)=5.56, p<.05$. Identity salience increased social obligation to larger society among collectivists.

As hypothesized, social obligation was higher for in-group; this effect was modified by the impact of identity salience and high collectivism on obligation to larger society. When the target of obligation was an individual, being high in collectivism and individualism reduced obligation. Unlike Study 1, we did not find a main effect of collectivism across contexts. Perhaps the Asian sample represents a group still in cultural flux.

\section{Latency of Obligation}

Mean latency. A main effect of identity salience was found, $F(1,71)=184.80, p<.001$, such that identity salience decreased latency. In addition, there is a significant two-way IND $\times$ COL interaction, $F(1,71)=4.25, p<.05$, such that the cultural accommodators (those high in both IND and COL) were the fastest in making judgments. When exposure to U.S. cultural context was used as the third between-subjects variable, we found a trend-level, three-way IND $\times$ COL $\times$ Exposure interaction, $F(2,67)=2.93, p=.06$, such that those who were least exposed to U.S. cultural context and high only in individualism took the longest time to make judgments about social obligation. This latency perhaps reflects the struggle of these participants to make sense of their obligation within a relatively new context. The ways in which the specific contexts of social obligation may interplay with cultural factors and identity salience in predicting social obligation judgment times were explored by means of the repeated measures ANOVAs discussed below.

Personal goal being interrupted (pleasure vs. achievement). We found a main effect of salience, $F(1,71)=184.80, p<$ .001 , and a two-way IND $\times$ COL interaction, $F(1,71)=4.25$, $p<.05$. Identity salience and cultural accommodation (being high in both collectivism and high individualism) reduced latency. The particular personal goal being interrupted had no impact on decision time. When exposure to U.S. context was substituted as the third between-subjects variable, we found a trend toward a three-way of IND $\times$ COL $\times$ Exposure interaction, $F(2,67)=2.93, p=.06$, such that high exposure to U.S. cultural context and cultural accommodation reduced latency and low exposure and high individualism increased latency. Identity salience and cultural accommodation thus play positive roles in social obligation for those coming from an Asian cultural perspective.

Target of obligation (individual vs. group). We found a trend toward a two-way COL $\times$ Identity Salience interaction, $F(1,80)=3.73, p=.06$. As hypothesized, collectivism reduced response time when identity was salient. When exposure was added as the third between-subjects variable, we found a twoway $\mathrm{COL} \times$ Exposure interaction, $F(1,77)=3.87, p=.05$, such that high COL and high exposure together reduced latency. As hypothesized, collectivism reduced response time when identity was salient. Exposure further reduced response time when collectivism was high.

Focus of obligation (in-group vs. larger society). We found a significant effect of identity salience, $F(1,71)=184.80, p$
$<.001$, as well as a significant two-way IND $\times$ COL interaction, $F(1,71)=4.25, p<.05$. In addition, we found a trendlevel IND $\times$ COL $\times$ Identity Salience interaction, $F(1,71)=$ $3.44, p=.07$, and a trend level Identity salience $\times$ Focus interaction, $F(1,71)=3.05 p<.10$. Again, making identity salient reduced decision time; decisions were fastest for cultural accommodators, especially when identity was salient. When exposure was added as a third between-subjects variable, we found a trend toward a significant three-way IND $\times$ COL $\times$ Exposure interaction, $F(2,67)=2.93, p=.06$, such that cultural accommodation reduced latency for the high-exposure group.

The latency data generally underscore the hypothesized positive role of cultural accommodation when identity was made salient and for the participants most exposed to U.S. cultural context.

\section{Confidence in Judgment}

Mean confidence. No main or interaction effects were found for the cultural factors, IND and COL, or for identity salience and exposure to U.S. context. The ways in which the specific contexts of social obligation may interplay with cultural factors and identity salience in predicting social obligation judgment times were examined by means of repeated measures analyses, as explained in the following sections.

Personal goal being interrupted (pleasure vs. achievement). As was the case with the level and latency repeated measure ANOVAs in Study 2, no main or interaction effects of IND, $\mathrm{COL}$, or identity salience were found, but participants were more confident that they would help when the goal being interrupted was academic, $F(1,75)=85.89, p<.001$. In addition, exposure to U.S. cultural context had an impact on confidence in one's social obligation, as evidenced by a COL $\times$ Exposed $\times$ Personal Goal interaction, $F(2,67)=3.06, p=.05$. The high collectivists who were most highly exposed to U.S. culture were the least likely to help when the personal goal was pleasure. Exposure to U.S. cultural context appears to have an impact on the importance of the pleasure-focused personal goals.

Target of obligation (individual vs. group). We found no main or interaction effects of IND, COL, or identity salience. When exposure was substituted as the third between-subjects measure, we found a trend toward a two-way Exposure $\times$ Target interaction, $F(1,67)=2.84, p=.06$, such that exposure reduced helping of groups, not of individuals.

Focus of obligation (in-group vs. larger society). We found a main effect of target, $F(1,71)=5.93, p<.05$, modified by a two-way Identity Salience $\times$ Target interaction, $F(1,71)=$ $30.74, p<.001$, and a three-way COL $\times$ Identity Salience $\times$ Target interaction, $F(1,71)=4.00, p<.05$. Identity salience increased confidence in helping larger society and decreased confidence in helping one's in-group; these effects were accentuated by collectivism.

We found relatively few effects of cultural frame or context with regard to confidence. However, the hypothesized positive impact of collectivism, when made salient, on social obligation to larger society was found.

\section{Discussion}

Overall, the findings from Study 2 are in line with the hypothesized impact of collectivism on social obligation, but only 
when identity was made salient and the focus of obligation was larger society. The hypothesized positive effect of cultural accommodation was found for response latency; that is, individuals high in both individualism and collectivism were faster in their response to the social obligation scenarios. In general, exposure to U.S. society played a role, such that exposure increased obligation-perhaps Study 2 findings are colored by the struggle of participants to find a niche in U.S. society and to feel the sense of belonging that may be a prerequisite to a sense of obligation. Identity salience increased obligation to larger society rather than simply strengthening the effect of cultural frame. Identity salience may function to increase impression management concerns and the desire to present one's group in a positive light.

\section{General Discussion}

Our focus in the studies reported above was on the ways in which individualism and collectivism influence social obligation. Clearly, a society cannot long survive if its members do not feel obligated or committed to it. The implied social contract between individual and group or society is such that each benefits from the other, and societies must each develop a way of creating and sustaining such a contract (e.g., Etzioni, 1993; Schwartz, 1996). Although all social obligation is assumed to be positive, questions arise as to the ability of a heterogeneous society to sustain social obligation to larger society and not only to the in-group (e.g., Fiske, 1991). This issue is particularly salient in the context of sectarian violence in Africa, the Middle East, and former Yugoslavia, and questions about the extent to which a focus on racial and ethnic difference within the U.S. may result in Balkanization, that is, a lack of a sense of overarching community and focus only on the in-group as well as a loss of focus on individual rights and responsibilities and a shift in focus to group rights (e.g., Ben-Dor, 1988). Some researchers have argued that democracy depends on the existence of a stable overarching identity, ("we are all Americans") within the context of fluid allegiances to interest groups (e.g., Oyserman, 1992; Sears, 1987) and that a sense of commitment to the larger national American societal community is a hallmark of individualism, not collectivism (e.g., Triandis, 1995; Wilkinson, 1992).

Americans are often described as individualists concerned with personal freedoms and attaining personal goals. This stance is often contrasted with an Asian, collectivist world view in which group harmony and connectedness are central concerns. Such collectivistic harmony, however, is to be maintained only with in-group members; the strong demarcation of in-group and out-group is especially detrimental in racially, ethnically, and culturally heterogeneous societies. In these societies, civil discourse is often strained, and analyses point to the existence of stable groups that result in ethno-politics that threaten the stability of democratic institutions by setting up collaboration only within the ethnic in-group and instilling a lack of trust in ethnic out-groups such that the overriding in-group of larger society becomes lost in the shuffle (e.g., Duckkit, 1996).

Recent work by Burnstein, Crandall, and Kitayama (1994) suggests that neo-Darwinian inclusive fitness calculations can predict altruism in situations where life is at stake. It seems plausible that collectivism as a world view developed in societies in which communal effort is required for the common good. We explored the implications of cultural hybridization, that is socialization into both individualistic and collectivist world views - for social obligation, arguing that collectivism may prime obligation, but only in culturally appropriate contexts, and that cultural hybridization may enhance obligation by making larger society a relevant target of obligation. Findings from Study 1 suggest the importance of collectivism in social obligation, and findings from Study 2 provide a partial replication of these results. Individualism played a less critical role, perhaps because although an individualistic cultural frame focuses attention on the self it does not make specific reference to obligation. Although individualism may not set up sanctions against obligation, this cultural frame does not seem to make social obligation a highly salient, personally relevant component of relational schemas.

Our sample participants were from two minority groups within the United States, both of whom can be described as having a collectivist or communal cultural heritage (Lipset, 1991; London \& Hirshfeld, 1991). In addition to differing in many aspects of particular cultural heritage, the groups also differed in the extent to which they were made up of recent immigrants to the United States. We hoped that this difference would shed light on the impact of exposure to U.S. culture as well as on the success of efforts to inculcate minority cultural values among those who have been in the United States for some time. In Study 1 we were unable to find a relationship between socialization to the minority culture and cultural frame, but in Study 2 we did find a relationship between exposure to U.S. cultural context and cultural frame such that greater exposure was related to lower levels of collectivism. These findings suggest that cultural hybridization involves inclusion of larger society as part of the in-group without loss of the social obligation that is built into collectivism. Our findings are clearly initial, yet they do provide evidence for the posited positive implications of collectivism and cultural hybridization for social obligation. In addition, these findings highlight the need to look more closely at the cultural framework of United States rather than assuming that socialization within U.S. society focuses on individualism only. To the extent that it "takes a village to raise a child' it is important to establish the extent to which members of this village feel obligated to commit resources to it. Future work should explore more specifically the content of relational schemas for both cultural minority and majority group members to document the extent to which these schemas contain not only expectations about interactions with specific others but also ways of being in the world that focus on commitment and obligation to groups or classes of others.

\section{References}

Ames, P., Dissanayake, W., \& Kasulis, T. (1994). Self as person in Asian theory and practice. Albany, NY: State University of New York Press.

Bachnik, J. (1992). Kejime: Defining a shifting self in multiple organizational modes. In N. Rosenberger (Ed.), Japanese sense of self ( $\mathrm{pp}$. 152-172). New York: Cambridge University Press.

Baldwin, M. (1992). Relational schemas and the processing of social information. Psychological Bulletin, 112, 461-484.

Batson, C. D. (1995). Prosocial motivation: Why do we help others? In 
A. Tesser (Ed.), Advances in social psychology (pp. 332-381). New York: McGraw-Hill.

Bellah, R., Madsen, R., Sullivan, W., Swidler, A., \& Tipton, S. (Eds.). (1985). Individualism and commitment in American life: Readings on the themes of habits of the heart. New York: Harper Torch Books.

Ben-Dor, G. (1988). Ethnopolitics and the Middle Eastern state. In M. Esman \& I. Rabinovich (Eds.), Ethnicity, pluralism, and the state in the Middle East (pp. 71-94). Ithaca, NY: Cornell University Press.

Berry, J. W. (1989). Psychology of acculturation. In J. J. Berman (Ed.), Nebraska Symposium on Motivation: Vol. 37. Cross-cultural perspectives (pp. 201-234). Lincoln: University of Nebraska Press.

Burnstein, E., Crandall, C., \& Kitayama, S. (1994). Some neo-Darwinian decision rules for altruism: Weighing cues for inclusive fitness as a function of the biological importance of the decision. Journal of Personality and Social Psychology, 67, 773-789.

Callero, P. (1986). Putting the social in prosocial behavior: An interactionist approach to altruism. Humboldt Journal of Social Relations, $13,15-32$.

Cameron, J. E., \& Lalonde, R. N. (1994). Self, ethnicity, and social group memberships in two generations of Italian Canadians. Personality and Social Psychology Bulletin, 20, 514-520.

Crocker, J., Luhtanen, R., Blaine, B., \& Broadnax, S. (1994). Collective self-esteem and psychological well-being among White, Black, and Asian college students. Personality and Social Psychology Bulletin, 20, 503-513.

Cushman, P. (1990). Why the self is empty: Toward a historically situated psychology. American Psychologist, 45, 599-611.

Dawes, R., Van de Kragt, A., \& Orbell, J. (1990). Cooperation for the benefit of us not me, or my conscience. In J. J. Mansbridge (Ed.), Beyond self-interest (pp. 97-110). Chicago: University of Chicago Press.

Duckitt, J. (1996, November). Relative deprivation and intergroup attitudes in South Africa before and after transition. Paper presented at the Group Dynamics Seminar, Research Center for Group Dynamics, University of Michigan, Ann Arbor.

Etzioni, A. (1993). Spirit of community: Rights, responsibilities and the communitarian agenda. New York: Crown.

Fiske, A. (1990). Structures of social life: The four elementary forms of human relations. New York: Free Press.

Fiske, A. (1991). The cultural relativity of selfish individualism: Anthropological evidence that humans are inherently sociable. In M. S. Clark (Ed.), Prosocial behavior: Review of personality and social psychology, Vol. 12 (pp. 176-214). Newbury Park, CA: Sage.

Fowers, B., \& Richardson, F. (1996). Why is multiculturalism good? American Psychologist, 51, 609-621.

Gergen, K. (1991). The saturated self: Dilemmas of identity in contemporary life. New York: Basic Books.

Gordon, M. (1964). Assimilation in American life. New York: Oxford University Press.

Gurin, P., Hurtado, A., \& Peng, T. (1994). Group contacts and ethnicity in the social identities of Mexicanos and chicanos. Personality and Social Psychology Bulletin, 20, 521-532.

Gutierrez, D. (1994). Ca-Clipper (Version 5.2) [Computer software]. New York: Wiley.

Hofstede, G. (1991). Empirical models of cultural differences. In N. Bleichrodt \& P. Drenth (Eds.), Contemporary issues in cross-cultural psychology (pp. 4-33). Berwyn, PA: Swets \& Zeitlinger.

Kagitcibasi, C. (1996). Family and human development across cultures. Mahwah, NJ: Erlbaum.

Kowalski, R. M., \& Wolfe, R. (1994). Collective identity orientation, patriotism and reactions to national outcomes. Personality and Social Psychology Bulletin, 20, 533-540.

LaFromboise, T., Coleman, H., \& Gerton, J. (1993). Psychological im- pact of biculturalism: Evidence and theory. Psychological Bulletin, $114,395-412$.

Latané, B., \& Darley, J. (1970). The unresponsive bystander: Why doesn't he help? New York: Appleton-Century-Crofts.

Liberman, K. (1986). The Tibetan cultural praxis: Brodhicitta thought training. Humboldt Journal of Social Relations, 13, 113-126.

Lipset, S. (1991). Introduction. In D. Gordis \& T. Ben-Horin (Eds.), Jewish identity in America (pp. xii-xv). Los Angeles: Wilstein Institute.

London, P., \& Hirshfeld, A. (1991). The psychology of identity formation. In D. Gordis \& T. Ben-Horin (Eds.), Jewish identity in America (pp. 31-50). Los Angeles: Wilstein Institute.

Lonner, W., \& Berry, J. (1989). Field methods in cross-cultural research. Beverly Hills, CA: Sage.

Markus, H., \& Kitayama, S. (1991). Culture and the self. Psychological Review, 98, 224-253.

Markus, H., Mullally, P., \& Kitayama, S. (1996). Selfways: Diversity in modes of cultural participation. Unpublished manuscript, Stanford University, Stanford, CA.

Meter, K. (1987). Crossing the border. Reflections. Minneapolis League of Women Voters.

Oyserman, D. (1992). Conflict and democracy in action. Small Group Research, 23, 259-277.

Oyserman, D. (1993). The lens of personhood: Viewing the self, others, and conflict in a multicultural society. Journal of Personality and Social Psychology, 65, 993-1009.

Oyserman, D., Gant, L., \& Ager, J. (1995). A socially contextualized model of African American identity: Possible selves and school persistence. Journal of Personality and Social Psychology, 69, 1216-1232.

Oyserman, D., \& Markus, H. (1993). The sociocultural self. In J. Suls \& A. Pratkanis (Eds.), Psychological perspectives on the self (Vol. 4, pp. 187-220). Hillsdale, NJ: Erlbaum.

Oyserman, D., \& Markus, H. (1996). The self as social representation. In S. Moscovici \& U. Flick (Eds.), Psychology of the social (pp. 38 70). Berlin: Roohlt Taschenbuch Verlag, GMbH.

Patel, N., Power, T., \& Bhavnagri, N. (1996). Socialization values and practices of Indian immigrant parents: Correlates of modernity and acculturation. Child Development, 67, 302-313.

Phillips, B. (1991). Sociological analysis of Jewish identity. In D. Gordis \& T. Ben-Horin (Eds.), Jewish identity in America (pp. 325). Los Angeles: Wilstein Institute.

Phinney, J. (1996). When we talk about American ethnic groups, what do we mean? American Psychologist, 51, 918-927.

Phinney, J., \& Cobb, N. (1996). Reasoning about intergroup relations among Hispanic and Euro-American adolescents. Journal of Adolescent Research, 11, 306-324.

Piliavin, J., \& Libby, D. (1986). Personal norms, perceived social norms, and blood donation. Humboldt Journal of Social Relations, 13, 159194

Sampson, E. (1988). The debate on individualism: Indigenous psychologies of the individual and their role in personal and societal functioning. American Psychologist, 43, 15-22.

Schwartz, S. (1990). Individualism-collectivism: Critique and proposed refinements. Journal of Cross.Cultural Psychology, 21, 139157.

Schwartz, S. (1996, August). New dimensions of culture: East is not east, west is not west. Paper presented at the Consequences of Cultures Consequences Symposium, 26 $6^{\text {th }}$ International Psychology Congress, Montreal, Quebec, Canada.

Schweder, R., \& Bourne, E. (1984). Does the concept of the person vary cross-culturally? In R. Schweder \& R. LaVine (Eds.), Culture theory: Essays on mind, self, and emotion (pp. 158-199). New York: Cambridge University Press. 
Sears, D. (1987). Political psychology. Annual Review of Psychology, $38,229-255$.

Shaver, P., Wu, S., \& Schwartz, J. (1992). Cross-cultural similarities and differences in emotion and its representation. In M. S. Clark (Ed.), Review of personality and social psychology, Vol. 13 (pp. 175-212). Newbury Park, CA: Sage.

Singalis, T. (1994). The measurement of independent and interdependent self-construals. Personality and Social Psychology Bulletin, 20, 580591.

Thompson, W., Cowan, C., \& Rosenhan, D. (1980). Focus of attention mediates the impact of negative affect on altruism. Journal of Personality and Social Psychology, 38, 291-300.

Triandis, H. (1989). The self and social behavior in differing cultural contexts. Psychological Review, 96, 506-520.

Triandis, H. (Ed.). (1995). Individualism and collectivism. Boulder, CO: Westview.
Triandis, H. (1996, August). Consequences of individualism and collectivism. Paper presented at the Consequences of Cultures Consequences Symposium, $26^{\text {th }}$ International Psychology Congress, Montreal, Quebec, Canada.

Triandis, H., Kashima, E., Shimada, E., \& Villareal, M. (1986). Acculturation indices as a means of confirming culturation differences. International Journal of Psychology, 21, 43-70.

Wilkinson, R. (Ed.). (1992). American social character. New York: Harper Collins.

Williamson, G., \& Clark, M. (1989). Providing help and desired relationship type as determinants of changes in mood and self-evaluations. Journal of Personality and Social Psychology, 56, 722-734.

Received November 18, 1996

Revision received July 3, 1997

Accepted July 7, 1997

\section{American Psychological Association SUBSCRIPTION Claims INFORMATION}

Today's Date:

We provide this form to assist members, institutions, and nonmember individuals with any subscription problems. With the appropriate information we can begin a resolution. If you use the services of an agent, please do NOT duplicate claims through them and directly to us. PLEASE PRINT CLEARLY AND IN INK IF POSSIBLE.

\begin{tabular}{l}
\hline PRINT FULL NAME OR KEY NAME OF INSTTTUTION \\
\hline ADDRESS \\
\hline STTY STATECOUNTRY \\
\hline
\end{tabular}

YOUR NAME AND PHONE NUMBER

TITLE

\section{MEMBER OR CUSTOMER NUMBER (MAY BE FOUND ON ANY PAST ISSUE LABEL)}

DATE YOUR ORDER WAS MAIIFD (OR PHONED)

PREPAID _ CHECK _ CHARGE

CHECKJCARD CLEARED DATE:

(If possible, send a copy, front and back, of your cancelled check to help us in our research of your claim.)

ISSUES: MISSING DAMAGED

Thank you. Once a claim is received and resolved, delivery of replacement issues routinely takes 4-6 weeks.

(TO BE FILLED OUT BY APA STAFF)

DATE RECEIVED:

ACTION TAKEN:

STAFF NAME:
DATE OF ACTION:

INV. NO. \& DATE:

LABEL NO. \& DATE:

Send this form to APA Subscription Claims, 750 First Street, NE, Washington, DC 20002-4242

PLEASE DO NOT REMOVE. A PHOTOCOPY MAY BE USED. 